\title{
EDUCAÇÃO AMBIENTAL NO ENSINO DE GEOGRAFIA: UMA CONTRIBUIÇÃO DO PIBID PARA ALUNOS DO ENSINO FUNDAMENTAL
}

Gildênia Lima Monteiro ${ }^{1}$

RESUMO: O presente estudo pretende demonstrar a contribuição do Programa Institucional de Iniciação à Docência (PIBID) para a percepção dos alunos sobre a relação existente entre a Educação Ambiental e a Geografia. O público alvo deste trabalho são alunos do ensino fundamental de uma escola pública em Teresina (PI)PI, onde se procedem as experiências do PIBID do subprojeto Geografia. No entanto, esse artigo propõe uma reflexão sobre a Educação Ambiental no ensino de Geografia, através da análise da percepção que os alunos possuem sobre as práticas simples relacionadas aos elementos do meio ambiente. Faz parte desse estudo ainda, propor algumas práticas de Educação Ambiental que possam ser utilizadas no ensino de Geografia. A metodologia utilizada para a realização desse artigo foi o trabalho de campo, realizado no ambiente escolar e a pesquisa bibliográfica.

Palavras-Chave: PIBID; Educação Ambiental; Ensino de Geografia.

${ }^{1}$ Universidade Estadual do Piauí, Teresina, PI: E-mail: gec.geografia.filosofia@hotmail.com

Revbea, São Paulo, V. 10, N 1: 281-290, 2015.

revista brasileira educação ambiental 


\section{Introdução}

O presente estudo tem como objetivo demonstrar a contribuição do PIBID para a percepção dos alunos sobre a relação existente entre Educação Ambiental e a Geografia. E a partir deste, analisar a Educação Ambiental sobre a perspectiva geográfica, e identificar o grau de percepção de alunos do ensino fundamental sobre as práticas ambientais. E por fim, pretende-se listar algumas práticas de Educação Ambiental que possam ser utilizadas no ensino de Geografia.

No subprojeto em questão, os pibidianos vivenciam diretamente os desafios da sala de aula, em especial na disciplina de Geografia, sendo responsáveis por fornecer auxílio didático-pedagógico ao professor da disciplina, e ainda por buscar mecanismos que facilitem o processo de aprendizagem pelos alunos nas aulas de Geografia. Nesse contexto, buscouse inserir questões sobre Educação Ambiental nas aulas de Geografia, afim de que os alunos compreendam a importância da mesma para suas práticas cotidianas.

A metodologia utilizada no presente estudo foi a pesquisa bibliográfica e pesquisa de campo a partir do auxílio pedagógico nas aulas de Geografia de uma turma de $7^{\circ}$ ano do ensino fundamental e ainda, por meio da aplicação de questionário com questões abertas para 29 alunos da série mencionada. A partir dos questionários aplicados buscou-se organizar os dados obtidos em formas de tabelas para melhor compreensão da percepção dos alunos sobre as questões ambientais.

\section{A Educação Ambiental na perspectiva geográfica}

A ciência geográfica desde sua origem vem demonstrando preocupações com as questões ambientais, iniciando através do estudo da relação homem $x$ natureza até uma construção do conceito de meio natural e da interferência humana neste ambiente. Assim, na origem da ciência geográfica "o homem era entendido como externo ao meio, ou externo à natureza. Ao longo do tempo, a geografia vai transformando sua compreensão e passa a pensar o ambiente como homem/sociedade e seu entorno [...]" (SUERTEGARAY, 2002, p. 116).

A partir dessa concepção nota-se que a ciência geográfica foi adaptando suas teorizações acerca da relação do homem com a natureza, passando a reformular suas concepções e trazendo para o centro de suas discussões a presença humana, que já estava demonstrando sua capacidade de interferência na transformação da natureza. Contudo, notou-se que houve um processo acelerado de apropriação e transformação do meio natural, sendo necessário se repensar o modo pelo qual o ser humano vem se apropriando deste espaço, de forma que: 
Ao longo de sua relação com o espaço a sociedade tem provocado sucessivas alterações, na medida em que, dele vem se apropriando, sendo a frequência, intensidade e área de abrangência dos impactos, determinadas pelo grau de desenvolvimento tecnológico e necessidades sociais [...] (LANDIM, 2011, p. 260).

Em meio a essas discussões sobre a interferência humana na natureza, verificou-se certa emergência pelas questões relacionadas ao meio ambiente, visto que emerge uma crise ecológica, tendo como fator principal a degradação dos recursos naturais, podendo comprometer a qualidade de vida das gerações futuras, considerando-se que esta crise "também é uma crise dos valores humanos, da ética em todas as dimensões, e traz a tona novos pensamentos, novos conflitos, novas possibilidades, novas soluções e novos comportamentos diante do planeta" (AZEVEDO, 1999, p. 68).

Diante dessa emergência socioambiental, compete à sociedade agir com uma postura diferenciada, a fim de tentar reparar os danos causados pela humanidade ao longo de sua história, pois "a crise ambiental exige a determinação de uma nova ética de comportamento humano, na qual o interesse coletivo define as formas de organização" (TOZONI-REIS, 2004, p.55). Nessa perspectiva, acredita-se que a Educação Ambiental é o método mais eficaz para buscar soluções e/ou alternativas que sensibilizem a sociedade quanto aos problemas socioambientais que estão ocorrendo no planeta nas últimas décadas. Deste modo, afirma-se que:

À escola cabe uma parcela de contribuição nessas novas buscas. Sendo um espaço privilegiado de informação, de transmissão e produção de conhecimentos, de criatividade, de possibilidades. Deve-se trabalhar na perspectiva da superação de visões distorcidas, ingênuas, reducionistas das novas gerações [...] (AZEVEDO, 1999, p. 68).

Acredita-se na eficácia da Educação Ambiental, assim, afirma Rodriguez (2009, p. 176) que:

A Educação Ambiental surge como uma necessidade no processo de salvar a humanidade de seu próprio desaparecimento e de ultrapassar a crise ambiental contemporânea. É um dos meios para se adquirir as atitudes, as técnicas e os conceitos necessários à construção de uma nova forma de adaptação cultural aos sistemas ambientais [...].

A Educação Ambiental "[...] é um processo de aprendizagem e comunicação das questões relacionadas com a interação dos seres humanos com o ambiente, tanto em âmbito global, natural, como no criado pelo homem" 
(RODRIGUEZ, 2009, p.175). Contudo, percebe-se a importância da Educação Ambiental no processo de sensibilização da sociedade, principalmente no âmbito escolar, pois "[...] falar de meio ambiente hoje tornou-se pauta obrigatória, não por um mero modismo, mas por uma necessidade de se compreender a complexidade dos fenômenos ambientais que afetam o planeta [...]" (AZEVEDO, 1999, p.79). A Educação Ambiental é compreendida de acordo com o leque de sua complexidade, dessa forma,

A sensibilização da sociedade, a incorporação do saber ambiental emergente no sistema educacional e a formação dos recursos humanos de alto nível foram considerados como processos fundamentais para orientar e instrumentar as políticas ambientais (LEFF, 2009, p. 222).

Em meio a essa discussão, a Educação Ambiental é concebida como processos por meio dos quais o indivíduo e a coletividade constroem valores sociais, conhecimentos, habilidades, atitudes e competências voltadas para a conservação do meio ambiente, bem de uso comum do povo, essencial à sadia qualidade de vida e sua sustentabilidade (BRASIL, 1999, p.1). Observa-se que a Educação Ambiental possui uma ligação estreita com a ciência geográfica, visando à qualidade de vida da população e a sustentabilidade por meio de atitudes práticas da sociedade.

Por meio dessa temática, a Geografia sempre esteve ligada às transformações ocorridas no espaço geográfico que envolvia a sociedade, de forma que, no ambiente escolar instiga o aluno a observar, analisar e compreender a sua modificação ao longo do tempo. Segundo os Parâmetros Curriculares Nacionais (PCN's) de Geografia, "a proposta de Geografia para estudo das questões ambientais favorece uma visão clara dos problemas de ordem local, regional e global, ajudando a sua compreensão e explicação, fornecendo elementos para a tomada de decisões e permitindo intervenções necessárias" (BRASIL, 1998, p.46). Contudo observa-se que todos os conteúdos relacionados ao meio ambiente podem ser abordados pelo olhar geográfico, e deste modo, inseridos no cotidiano escolar dessa disciplina.

Segundo a Política Nacional de Educação Ambiental a "Educação Ambiental será desenvolvida como uma prática educativa integrada, contínua, e permanente em todos os níveis e modalidades do ensino formal' (BRASIL, 1999, p.4), demonstrando a importância de a Educação Ambiental estar inserida no cotidiano escolar, destacando-se ainda que esta não possa ser concebida como uma disciplina no currículo escolar, mas que, deve ser uma prática interdisciplinar, comum à todas as disciplinas, para tanto, "[...] a Educação Ambiental aponta para propostas pedagógicas centradas na conscientização, mudança de comportamento, desenvolvimento de competências, capacidade de avaliação e participação dos educandos [...]" (JACOBI, 2004, p.31). 
Em meio a toda essa discussão busca-se uma Educação Ambiental crítica, que incorpore novos valores e métodos, que seja capaz de mobilizar a sociedade para a emergência da crise ambiental, pois se espera por um despertar da humanidade para as causas ambientais e sociais, mesmo parecendo utopia, mas alguns autores defendem esta vertente da Educação Ambiental, isso por meio de:

[...] uma educação capaz de gerar uma consciência e capacidades próprias para que as populações possam apropriar-se de seu ambiente como uma fonte de riqueza econômica, de prazer estético e de novos sentidos de civilização; de um novo mundo onde todos os indivíduos, as comunidades e as nações vivam irmanados em laços de solidariedade e harmonia com a natureza (LEFF, 2009, p. 252)

Portanto, a Educação Ambiental, é vista pela Geografia como a ferramenta para que os cidadãos tornem-se seres mais críticos e com capacidades de ação diante de suas responsabilidades. Essa criticidade é adquirida inicialmente a partir da descoberta da realidade vivenciada pelos educandos a fim de facilitar o seu processo de conhecimento a partir do seu cotidiano, pois segundo Penteado (1997, p. 53),

Uma coisa é ler sobre o meu meio ambiente e ficar informado sobre ele, outra é observar diretamente o meu meio ambiente, entrar em contato direto com os diferentes grupos sociais que o compõem, observar como as relações sociais permeiam o meio ambiente e o exploram, coletar junto às pessoas informações sobre as relações que matem com o meio ambiente em que vivem, enfim, apreender como a sociedade lida com ele.

Para tanto, acredita-se que o ponto inicial para essa conscientização e/ou sensibilização ocorre por meio de incentivos a práticas ambientais com crianças e adolescentes no ambiente escolar, partindo de um princípio clássico da Geografia, compreender o mundo a partir da realidade vivenciada pelo aluno em seu cotidiano, levando o seu aprendizado para a família e comunidade em geral.

\section{Resultados e discussões}

$\mathrm{Na}$ parte prática do presente estudo, procurou-se analisar o grau de percepção de uma turma de alunos do ensino fundamental sobre o seu entendimento acerca das questões ambientais de sua vivência. Para tanto, foi aplicado um questionário aberto aos 29 alunos de uma turma de $7^{\circ}$ Ano/Ensino Fundamental, como forma de diagnosticar o conhecimento inicial que estes adolescentes dispunham sobre o conceito de Geografia, conceito de Meio Ambiente, e questões mais específicas como a importância da Água, e problemas ambientais urbanos comuns como o Lixo, sendo temas presentes em sua realidade vivenciada. 
Ao perguntar sobre o que seria a Geografia para eles, obtivemos como maior número de vezes citados (11) a matéria que estuda mapas, o globo, o meio ambiente, o lixo e a população brasileira. Em seguida, foi citado 5 vezes que a geografia era "um estudo geográfico". Destacando-se apenas 3 respostas que citaram que esta ciência estuda o espaço geográfico. Demonstrando um nível baixo de compreensão do que vem a ser esta ciência e de seu papel para a sociedade (Tabela 1). A ciência geográfica, ao buscar estudar o espaço geográfico, a partir da compreensão da relação entre sociedade e natureza, sempre esteve voltada para a questão ambiental, buscando compreender como essas relações interferem no modo de relacionamento da sociedade como o meio em que vive (CANALI, 2002).

Tabela 1: Conceito de Geografia.

\begin{tabular}{lc}
\hline \multicolumn{1}{c}{ RESPOSTA } & № de VEZES CITADO \\
\hline Matéria que estuda mapas/globo/meio & 11 \\
ambiente/lixo/população brasileira. & 5 \\
É um estudo geográfico. & 4 \\
Matéria que estuda os países e estados do Brasil. & 1 \\
Mapa e GPS. & 3 \\
Vários mapas sobre o Brasil e o mundo. & 3 \\
Matéria que estuda o espaço geográfico. & 2 \\
Matéria legal, que estuda tudo, todas as coisas. & Fonte: Monteiro (2013). \\
\hline
\end{tabular}

Fonte: Monteiro (2013).

Ao perguntar sobre o Entendimento sobre o que viria a ser o Meio Ambiente, a resposta mais citada (11) foi que meio ambiente são árvores, vegetação, animais e o homem. Logo depois se observou que foram citadas 8 vezes o conceito de que este seria um lugar que devemos cuidar para não atingir a sociedade. Sob este aspecto, observa-se que é muito restrita a visão dos alunos sobre o meio ambiente, limitando-se apenas às paisagens naturais, que em alguns casos agrega o homem também (Tabela 2).

Tabela 2: Entendimento sobre Meio Ambiente.

\begin{tabular}{lc}
\hline \multicolumn{1}{c}{ RESPOSTAS } & № DE VEZES CITADO \\
\hline Árvores, vegetação, animais e ser humano. & 11 \\
& \\
Lugar que devemos cuidar para não atingir a sociedade. & 8 \\
$\begin{array}{l}\text { Que não devemos poluir, não jogar lixo (deve ser } \\
\text { preservado) }\end{array}$ & 7 \\
Precisamos do meio ambiente para sobreviver. & 2 \\
Não sabe & 1 \\
\hline
\end{tabular}

Fonte: Monteiro (2013).

Ao falar sobre meio ambiente percebe-se que ainda existe uma concepção muito naturalista, que se encontra fixada no processo de ensino aprendizagem tradicional. No entanto, "a educação interdisciplinar entendida como a formação de mentalidades e habilidades para apreender a realidade 
complexa, reduziu-se à incorporação de uma 'consciência ecológica' no currículo tradicional." (LEFF, 2009, p. 243). É dessa forma que se encontra a Educação Ambiental na educação básica, onde a maioria dos alunos dispõe apenas de uma visão generalizada de meio ambiente.

Ao perguntar sobre os problemas ambientais encontrados próximo à residência e à escola dos alunos, a resposta mais citada (13) foi o acúmulo de lixo nas ruas. E logo em seguida, foram citados 8 vezes respostas relacionadas a falta de saneamento básico nas ruas, como esgotos sujos, galerias a céu aberto, lixo nas ruas (Tabela 3).

Falar sobre os problemas ambientais urbanos é um desafio, pois na realidade, muitos dos alunos não dispõem de uma visão integrada de meio ambiente e a ação humana. Porém, esse questionamento é pertinente a realidade que cada aluno observa no seu dia a dia, o que seria de fácil compreensão encontrar pela cidade artifícios da ação indevida do homem para com o meio ambiente urbano.

Tabela 3: Problemas Ambientais Encontrados próximo à Residência e à Escola.

\begin{tabular}{lc}
\hline \multicolumn{1}{c}{ RESPOSTAS } & NÚMERO DE VEZES CITADO \\
\hline Acúmulo de Lixo nas Ruas & 13 \\
Falta de Saneamento Básico & 8 \\
Mau cheiro por conta do lixo acumulado & 5 \\
Árvores Queimadas & 1 \\
Águas Poluídas & 1 \\
Nenhum & 1 \\
\hline
\end{tabular}

Fonte: Monteiro (2013).

Ao perguntar sobre a Importância da Água no Cotidiano a resposta mais citada (13) foi que ela é necessária para a sobrevivência humana. Em seguida, foram citadas 11 vezes sobre a utilização da água para as utilidades domésticas (Tabela 4).

Tabela 4: Importância da Água no Cotidiano.

\begin{tabular}{lc}
\hline \multicolumn{1}{c}{ RESPOSTAS } & № DE VEZES CITADO \\
\hline Necessária para a Sobrevivência Humana & 13 \\
Utilidades Domésticas & 11 \\
Necessidade de Preservar a Água & 5 \\
\hline
\end{tabular}

Fonte: Monteiro (2013).

A água é um elemento que compõe o meio natural nas cidades, sendo imprescindível deixar de citá-la nessa discussão, devido a sua importância para a sobrevivência e existência da vida no planeta. Sobre o aspecto da sua qualidade afirma-se que, "pode-se avaliar o grau de desenvolvimento de um povo pela qualidade da água e dos serviços de saneamento que lhes são oferecidos" (DIAS, 2004, p.317)

Ao questionar sobre as atitudes individuais da prática de jogar o lixo apenas no lixo, o maior número de alunos respondeu que sim (16). Em seguida, 11 vezes foi citado que às vezes seguem essa prática, sendo que 
alguns justificaram por conta do esquecimento e acabam jogando em qualquer lugar, e ainda por existirem lugares em que não se encontram lixeiras disponíveis. E com um número menor de respostas (2) inferiram que não costumam fazer essa prática, justificando por falta de atenção no ato de jogar o lixo nas ruas, e ainda por esquecimento.

Entretanto, daqueles que responderam que fazem essa prática, poucos sabem o real valor dessa simples atitude para o meio ambiente. Pois poucos conseguiram exemplificar a resposta com as consequências de uma atitude imprópria, como esgotos entupidos, alagamentos, doenças trazidas ao ser humano, enfim, poucos são aqueles que têm uma noção dos riscos ao meio ambiente.

A questão do lixo/resíduos sólidos atualmente vem ganhando destaque nacional, por conta do crescente volume de lixo gerado nas cidades, constituindo-se em "um dos grandes problemas na maioria dos municípios brasileiros [...] Como sempre, é a comunidade que vai sofrer os maiores impactos ambientais pela falta de saneamento dos resíduos [...]" (DIAS, 2004, p. 287)

Portanto, ao longo dessa pesquisa, buscou-se abordar questões inerentes ao ensino de geografia e ao cotidiano dos alunos pesquisados, como forma de aproximar o máximo possível da realidade destes à proposta de Educação Ambiental no ensino de geografia, considerando-se as possibilidades de aplicação de novas metodologias possíveis de serem aplicadas em sala de aula.

\section{Ensino de Geografia e práticas de Educação Ambiental}

É de grande importância a realização de atividades práticas ambientais na escola, fazendo com que os alunos compreendam a necessidade do envolvimento da comunidade escolar nas questões relacionadas ao meio ambiente, "[...] no caso da Educação Ambiental, é importante compreender como as pessoas pensam, aprendem e agem no meio em que vivem [...]." (HIGUCHI, 2004, p. 64), principalmente nas cidades, em que o meio ambiente urbano encontra-se em um estado instável de degradação.

A ausência de trabalhos de Educação Ambiental é comum no âmbito escolar, sendo o Dia do Meio Ambiente (5 de Junho) o único dia destinado à campanhas e informes sobre a necessidade de preservação do meio ambiente. No entanto, percebe-se que é necessário ir além dessas atitudes imediatistas, que não resolvem nem minimizam os problemas atuais. O meio ambiente deve ser algo de constante estudo e informações à sociedade sobre seu processo de destruição.

Nas aulas de Geografia, o PIBID proporciona aos bolsistas a capacidade de criação de projetos ambientais sobre questões que envolvam a realidade dos alunos, tais como oficinas de reciclagem, palestras sobre preservação dos nossos rios, preservação da água e de energia elétrica, consumo exagerado da 
população que gera aumento na quantidade de resíduos, poluição do ar, poluição sonora, desmatamento, entre outros.

Além das Oficinas e Palestras, podem ser inseridas metodologias mais simples na exposição de alguns conteúdos geográficos, assim como o trabalho com Músicas sobre as temáticas em questão, trabalhos como História em Quadrinhos (HQ's), Criação de Desenhos, Cartazes e Panfletos para ajudar na sensibilização de outras crianças e jovens, o uso de jornais e revistas, trabalhos com músicas por meio da construção de paródias, o uso de Recursos Audiovisuais, através da inserção de Vídeos, Filmes e Documentários sobre as questões ambientais, além da construção de projetos interdisciplinares coletivos, os quais envolvam alunos e professores de diversas áreas do conhecimento.

São várias as formas de atividades que possam ser desenvolvidas abordando a Educação Ambiental de forma interdisciplinar visando atingir a coletividade social. Assim como afirma Azevedo (1999, p.81):

[...] não existe uma única maneira, uma metodologia apropriada, fórmulas mágicas, mas a criatividade, a ousadia e o uso de recursos simples [...], podem auxiliar para que determinadas temáticas sejam mais fáceis de ser abordadas, constituindo-se em momentos ricos de aprendizagem.

Portanto, percebe-se o quão grandioso é o leque de metodologias disponíveis que possam ser aplicadas no ensino de Geografia, sendo válido observar o público a que se destina cada ferramenta utilizada e um planejamento prévio e organização na construção dos métodos utilizados para que a atividade consiga alcançar seus devidos objetivos.

\section{Conclusão}

Portanto, a partir dos resultados obtidos observa-se que o grau de entendimento da maior parte dos alunos é ainda é deficiente, demonstrando o nível de informações que dispõem sobre as práticas de Educação Ambiental. Porém, essa é uma realidade que precisa ser repensada e enfrentada no contexto da Geografia, como matéria escolar, e que está lidando com conteúdos bem próximos à realidade dos alunos. Faz-se necessário uma prática interdisciplinar que envolva as questões ambientais como tema relevante para o conhecimento da sociedade, que ainda se encontra muito desinformada quanto às atitudes que devem tomar relacionada à preservação da natureza.

Porém, existem aqueles alunos, que mesmo sendo muito jovens, demonstram um grau de entendimento maior sobre os problemas ambientais, fazendo-se necessário aprimorar essas ideias para que possam internalizá-las e ter consciência do papel que devem desempenhar. Dessa forma, o caminho a ser percorrido é traçado por meio da escola, do acesso à educação e à 
informação da sociedade em geral. Sendo essa, uma preocupação pertinente na área de atuação da ciência geográfica.

Faz-se necessário utilizar metodologias variadas para atrair a atenção de crianças e jovens para essas questões ambientais, de forma que o aprendizado recebido no ambiente escolar seja repassado para a sua família e comunidade em geral, fazendo com que, a informatização chegue a toda a sociedade para que esta saiba definir o seu papel no processo de preservação dos recursos naturais para a melhoria da sua qualidade de vida.

\section{Referências}

AZEVEDO, G.C. Uso de Jornais e Revistas na Perspectiva da Representação Social de Meio Ambiente em Sala de Aula. In: REIGOTA, M. (org.). Verde Cotidiano: o meio ambiente em discussão. Rio de Janeiro: DP\&A, 1999, p. 6782.

BRASIL, Secretaria de Educação Fundamental. Parâmetros Curriculares Nacionais: Geografia (PCN's). Brasília: MEC/SEF, 1998.

BRASIL, Lei n. 9.795, de 27 de abril de 1999. Política Nacional de Educação Ambiental. Brasília, DF, 1999.

CANALI, N.E. Geografia Ambiental: desafios Epistemológicos. In: MENDONÇA, F.; KOZEL, S. (orgs.). Elementos de Epistemologia da Geografia Contemporânea. Paraná: editora UFPR, 2002, p.165-186.

DIAS, G.F. Educação Ambiental: princípios e práticas. 9. ed. São Paulo: Gaia, 2004.

HIGUCHI, M.I.G.; AZEVEDO, G.C. Educação como Processo na Construção da Cidadania Ambiental. Revista Brasileira de Educação Ambiental. Brasília: Rede Brasileira de Educação Ambiental, n. 0, Trimestral, p. 63-70, 2004.

JACOBI, P. Educação e Meio Ambiente: transformando as práticas. Revista Brasileira de Educação Ambiental. Brasília: Rede Brasileira de Educação Ambiental, n. 0. Trimestral, p. 28-35, 2004.

LEFF, E. Saber Ambiental: sustentabilidade, racionalidade, complexidade, poder. Tradução de Lúcia Mathilde Endlich Orth. 7. ed. Petrópolis: Vozes, 2009.

PENTEADO, H.D. Meio Ambiente e Formação de Professores. 2. ed. São Paulo: Cortez, 1997, (Col. Questões da Nossa Época, v. 38).

RODRIGUEZ, J.M.M.; SILVA, E.V.. Educação Ambiental e Desenvolvimento Sustentável: problemática, tendências e desafios. Fortaleza: Ed. UFC, 2009.

SUESTEGARAY, D.M.A. Geografia Física (?), Geografia Ambiental (?) ou Geografia e Ambiente (?). In: MENDONÇA, F.; KOZEL, S. (orgs.). Elementos de Epistemologia da Geografia Contemporânea. Paraná: Editora UFPR, 2002, p. 111-120.

TOZONI-REIS, M.F.C. Educação Ambiental: natureza, razão e história. Campinas: Autores Associados, 2004, (Col. Educação Contemporânea). 